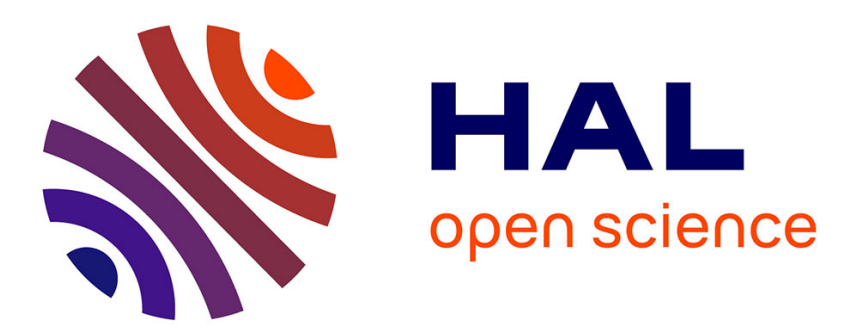

\title{
Making Sense of scientific claims in advertising. A study of scientifically aware consumers
}

\author{
Rachel E. Dodds, Efrat Tseëlon, Emma L.C. Weitkamp
}

\section{To cite this version:}

Rachel E. Dodds, Efrat Tseëlon, Emma L.C. Weitkamp. Making Sense of scientific claims in advertising. A study of scientifically aware consumers. Public Understanding of Science, 2008, 17 (2), pp.211-230. 10.1177/0963662506065559 . hal-00571098

\section{HAL Id: hal-00571098 \\ https://hal.science/hal-00571098}

Submitted on 1 Mar 2011

HAL is a multi-disciplinary open access archive for the deposit and dissemination of scientific research documents, whether they are published or not. The documents may come from teaching and research institutions in France or abroad, or from public or private research centers.
L'archive ouverte pluridisciplinaire HAL, est destinée au dépôt et à la diffusion de documents scientifiques de niveau recherche, publiés ou non, émanant des établissements d'enseignement et de recherche français ou étrangers, des laboratoires publics ou privés. 


\title{
Making Sense scientific claims in advertising. A study of scientifically aware consumers
}

\author{
Rachel E. Dodds, Efrat Tseëlon and Emma L.C. Weitkamp
}

Evidence that science is becoming increasingly embedded in culture comes from the proliferation of discourses of ethical consumption, sustainability, and environmental awareness. Al Gore's recent award, along with UN's Inter-governmental Panel on Climate Change (IPCC) of the Nobel peace prize - provided a recent high profile linking of consumption and science. It is not clear to what extent the public at large engages in evaluating the scientific merits of the arguments about the link between human consumption and global environmental catastrophes. But on a local scale, we are routinely required to evaluate, scientific and pseudoscientific claims in advertising. Since advertising is used to sell products, the discourse of scientifically framed claims is being used to persuade consumers of the benefits of these products. In the case of functional foods and cosmetics, such statements are deployed to promote the health benefits and effectiveness of their products. This exploratory study examines the views of British consumers about the scientific and pseudoscientific claims made in advertisements for foods, with particular reference to functional foods, and cosmetics. The participants in the study all worked in scientific environments, though they were not all scientists. The study found that scientific arguments that were congruent with existing health knowledge tended to be accepted while pseudoscientific knowledge was regarded skeptically and concerns were raised over the accuracy and believability of the pseudoscientific claims. It appears that scientific awareness may play a part in consumers' ability to critically examine scientifically and pseudoscientifically based advertising claims.

\section{Introduction}

Two new ways to lower cholesterol. (Flora Pro-Activ advertisement)

Advertising claims such as that shown above imply that consumers will reap health benefits from eating a particular food, possibly without making any other dietary modifications. Such claims are typically made for the class of foodstuffs referred to in the UK as functional foods. This class of product can be defined as foods for which functional claims are made (such as lowering cholesterol). Such claims must be supported by appropriate scientific evidence. In the UK, the Joint Health Claims Initiative maintains a voluntary code of practice relating to the marketing of functional foods (see below). Even with this voluntary regulation, the advertising for such products may be seen as blurring the distinction between functional foods and medicines and raises questions about consumers' interpretation of health and science based advertising claims (Kwak and Jukes, 2001a; Klompenhouwer and van den Belt, 2003). Indeed, 
Bäckström et al. (2003) found that consumers associate the term medicine with functional foods. Yet, from a regulatory perspective, functional foods are clearly different from medical foods (which require special labeling and are used under medical supervision) or pharmaceuticals (Kwak and Jukes, 2001b). Research shows that in many cases, claims made for functional foods are misleading and deceptive (Harrison and Brown, 2003). Similar research shows that consumers find it difficult to interpret nutrient claims made in advertisements (Roe et al., 1999; Andrews et al., 2000).

Health, scientific and pseudoscientific claims are also found in advertising for cosmetics. Examples include claims such as,

- "Incorporates encapsulated sunscreens to help shut out aging UVA and burning UVB rays"-Clinique, Advanced Stop Signs Eye Preventive Cream SPF 15 (an example of scientific and health claims);

- "Bikini Celluli-Diet—an essence that helps to "burn fat"”-Dior, Bikini Celluli-Diet (an example of pseudoscientific claims).

There is an essential factual difference between food and cosmetics. While food (especially of the unprocessed kind) is undoubtedly a necessity product whose benefit is undisputed, many cosmetics are more of a luxury product whose benefit lies more in the realm of image and "feel good" factor, while others, such as sunscreens, have health benefits. The health claims made for cosmetics are often similar to those made for functional foods in the way that they deploy science and scientific language to convey a selling message. Research, such as Harrison and Brown's (2003) findings, indicates that claims made for functional foods are sometimes misleading. If these findings are extrapolated to similar claims made for cosmetics, it is possible that some consumers will also find the health claims made for cosmetics misleading or difficult to interpret. Furthermore, cosmetics and functional foods both sit within two contrasting cultural narratives: "beauty system" and "health conscious culture."

The regulation of advertising in the UK seeks to safeguard consumers' access to accurate information to allow them to make informed choices. However, for both product categories, these are voluntary codes of practice. Cosmetics advertisements are subject to the same regulation as most other consumer products via the Independent Television Commission (ITC), Radio Authority or Advertising Standards Authority (non-broadcast media), which focus on whether the advertising is legal, decent, truthful and honest (ASA, 2003). Functional foods are subject to an additional voluntary code of practice administered by the Joint Health Claims Initiative (JHCI), which provides for health claims to be assessed based on scientific evidence. The JHCI code, which covers all non-medicinal foods, distinguishes between health claims, which are allowed provided they are truthful and do not mislead consumers, and medicinal claims (claims to prevent, treat or cure disease) which are prohibited (JHCI, 2005).

Furthermore, European legislation relating to functional foods reflects the view that consumers should be able to make informed choices (Klompenhouwer and van den Belt, 2003). Enabling consumers to make informed choices is also reflected in the UK government's interest in promoting the public understanding of science (Royal Society, 1985; House of Lords, 2000). This movement is based on the notion that greater understanding of science will lead to improved public and private decision-making.

\section{Advertising claims processing}

Both food and cosmetics are so called "experience" products, products that can only be evaluated after purchase. This contrasts with "search" products (which include consumer durables 
such as cars and white goods). Search products can be evaluated before purchase, through analyzing, for example, advertising. Economics of Information theory suggests that consumers attend to and "process" information in advertisements differently depending on whether they are search or experience products (Ford et al., 1990; Franke et al., 2004). This theory also suggests that consumers will be more skeptical of information that is difficult or costly to evaluate before a purchase is made and that consumers will be more skeptical of subjective claims than objective claims (Ford et al., 1990). Furthermore, information claims (sometimes referred to as credence claims) which are difficult to evaluate, such as claims for specific health benefits of functional foods or improvements in cosmetic appearance, may be viewed more skeptically. Further, in the context of Economics of Information theory, scientific information that is applied to "experience" products (e.g. food and cosmetics) may have one of two effects: it may be viewed skeptically because it is difficult to validate, or it may be viewed positively because it is seen as objective.

Another key factor in determining message comprehension is message credibility (Heesacker et al., 1983). If consumers do not believe the message, they are less likely to purchase the product. Several factors influence the believability of advertisement claims, including familiarity with the product or brand (Alba and Hutchinson, 1987). Holbrook (1978) argues that cognitive evaluation of the content of the advertisement is an essential part of consumers' evaluation of the product.

Petty and Cacioppo (1986) and Chaiken et al. (1989) found that the level of involvement with the purchasing decision influenced the effectiveness of different advertising messages. Argument and logic-based strategies were found to be most effective for purchases where there is a high level of consumer involvement. When involvement is low, consumers use peripheral cues or heuristic approaches, and are more influenced by subjective claims. Food products are generally considered low risk, low involvement purchases with a high level of routine repeat purchasing behavior. Many cosmetics products also fall into this category, though cosmetics products' intimate connection with issues of self esteem (via personal appearance) may increase the level of "involvement" with these products. It is also clear from cosmetics advertising, which relies heavily on image, that advertisers usually appeal to heuristic approaches, such as source credibility, message length and aesthetic appeal. Scientific jargon and pseudoscientific language may also be used heuristically by consumers. Thus, rational logic-based scientific arguments for functional foods and cosmetics would not be predicted to be processed by consumers in a systematic or complex way.

Research also suggests that more knowledgeable consumers encode and use information in terms of specific content rather than more abstract concepts (Brucks et al., 1984). Prior knowledge relating to the advertising claim also aids simplification and may lead to more accurate interpretation of the claim (Alba and Hutchinson, 1987). Our study focused on the interpretation and the persuasive effect of specific content relating to either scientific or pseudoscientific claims. In this exploratory investigation, participants were chosen who are familiar with scientific discourse. The logic behind the choice of such an "atypical" group was "the test of the stronger version," that is the possibility of establishing that if a scientifically savvy clientele finds it difficult to interpret scientific and pseudoscientific advertising claims, then a lay public is even more likely to find it difficult to navigate such claims. Thus, this provides a yardstick against which the responses of an audience less familiar with scientific language could be gauged.

Anita Roddick, the founder of The Body Shop, believes that the beauty industry has a vested interest in dressing its products with scientific prestige, and in concealing from the consumer that price is irrelevant: any moisturizing cream is equally effective (Roddick, 1991). She believes that some cosmetics advertisers seek "... mystification with pseudo-scientific, hi-tech jargon ('contains DNA22-b, the astonishing new formula!')" (Roddick, 1991: 11). 
While this is one cosmetics producer's view, it provided a starting point for this investigation into consumers' processing of scientific and pseudoscientific advertising claims.

This exploratory study investigates the interpretation of and interaction with the scientific and pseudoscientific messages contained in advertisements for functional foods and certain cosmetics. In particular, our study examined the credibility of scientific data as an advertising tool. We sought to:

1. Compare women's responses to advertisements for cosmetics and functional foods;

2. Evaluate whether women find scientific and pseudoscientific advertising claims made for food products credible;

3. Evaluate whether women find scientific and pseudoscientific advertising claims made for cosmetics credible.

\section{Methodology}

The credibility of science and health claims in advertisements was evaluated qualitatively. This allowed exploration of general attitudes to food and cosmetics, providing a background for a discussion of the credibility and attitudes toward health claims and advertising claims based on scientific and pseudoscientific statements. In addition, qualitative methods allow an in-depth exploration of attitudes and beliefs. Focus groups were chosen as they allow new concepts to be explored collectively. The focus group is a technique that involves a moderator-facilitated discussion among multiple participants about a specified topic of interest. Focus groups allow researchers to learn about the meaning of a construct from the perspective of the target population under study. Focus groups offer many potential advantages in comparison to one-to-one interviews - among them the fact that participants respond to questions posed not only by the moderator but also by other focus group participants. The interaction among focus group members means that a more in-depth discussion of events may be elicited than can be obtained in a one-to-one interview, in which a sole participant answers the questions of an interviewer (Greenbaum, 1998). This makes focus groups more than simply the sum of separate individual interviews (Morgan, 1996a,b). In addition, because participants may feel more comfortable discussing experiences with similar others, a more open and honest discussion might be triggered as a result. Basch (1987) suggested that data generated in focus group discussion can aid in the planning and presentation of health education programs for targeted populations. In fact, Seal, Bogart and Ehrhardt (1998) found that while a greater range and richness-depth of themes was present in the individual setting-dynamic interactions in the focus group setting provided insight beyond the content themes.

The focus group approach does raise some problems for a study of advertisements in that participants are asked to pay particular attention to advertisements pre-selected by the researchers. Thus, a focus group does not mimic the natural setting in which magazine advertisements would be consumed (for example by a person quickly flicking through a magazine who may read little or none of the text accompanying the advertisement and may pay fleeting attention to the visual imagery). However, this study sought to investigate how people interact with scientific and pseudoscientific arguments presented in the advertisements. This need for interaction presupposes that the consumer has read the advertisement and paid some attention to the messages contained therein. While it is clear that participants in this study are likely to have spent longer scrutinizing the advertisements than they would if encountered at home, time pressure was applied during the focus group to limit this scrutiny. Furthermore, advertisers themselves must hope that a proportion of potential purchasers will read the text of the advertisement in order for the arguments provided therein to have an effect. 
For the purpose of the study, the method of focus group data analysis chosen consisted of all four options outlined by Krueger (1998): transcript-based analysis, tape-based analysis, notebased analysis, and memory-based analysis. The reported results consist of a combination of raw data, description, interpretation, and recommendations. Finally, owing to the small amount of transcript material, simple manual indexing was preferred as an alternative to a qualitative data analysis package.

The research should not be seen as a comprehensive investigation but as an initial exploration designed to indicate trends and processes.

\section{Participant recruitment}

Three focus groups were conducted each consisting of 4-6 female participants. Women were chosen for this study because they represent the majority of purchasers of cosmetics products and are the main food shoppers in most households. The focus groups were homogeneous, consisting of people of similar age, with a similar level of scientific background and similar work environment. An inclusion criterion for the focus groups consisted of a degree of exposure to science through work and/or educational background. This was defined as having studied a science (to at least age 16) and working in a science-oriented environment (though not necessarily having a direct role as a "scientist"). Participants came from a variety of roles that encompassed scientist/researcher roles, science communicator roles and administrative/support roles. Two of the three focus groups included participants from a range of employment backgrounds, while one focus group consisted entirely of women in administrative/support roles. All focus groups contained a mixture of people who were well known to each other and people who were less familiar. Subjects were recruited through their workplace by word of mouth and e-mail. They were told that they would be shown advertisements for food and cosmetics products and asked for their opinions.

The three groups had the following characteristics:

- Group 1-composed of five women under age 30. All work in either environmental science or health science environments. Three had or were studying for postgraduate qualifications while the remaining two studied science to age 16 and were involved in administration for research groups. All described themselves as interested in the environment and/or health.

- Group 2-composed of four women under age 30. All work in administrative roles in a science department. These participants had studied science subjects to age 16 (1), age 18 (1) and at undergraduate level (2).

- Group 3-composed of six women aged 25-50. All work in a science center. The group included an equal distribution of women studying science to age 16, at undergraduate level and at postgraduate level. This group included women from administrative roles as well as those involved in the explanation of science to visitors.

Data from the three groups are analyzed as a whole, providing an indication of the views and experience of a scientifically aware consumer body. This allowed an exploration of commonalities of experience amongst the three groups. No specific differences were noted between the three groups during the analysis.

\section{Advertising stimulus materials}

In this study, advertisements for food and cosmetics were included which trade on the territory that lies on the verge of the scientific respectability of medicines. Thus, a margarine 
Table 1. Women's magazines from which advertisements were selcted

\begin{tabular}{lcc}
\hline Magazine & $\begin{array}{c}\text { Target audience- } \\
\text { social class }^{\mathrm{a}}\end{array}$ & $\begin{array}{c}\text { Target audience- } \\
\text { age profile (years) }\end{array}$ \\
\hline New Woman & $\mathrm{A}, \mathrm{B}, \mathrm{C} 1$ & $15-34$ \\
Top Santé & $\mathrm{A}, \mathrm{B}, \mathrm{C} 1$ & $15-54$ \\
She & $\mathrm{A}, \mathrm{B}, \mathrm{C} 1$ & $15-44$ \\
Marie Claire & $\mathrm{A}, \mathrm{B}, \mathrm{C} 1$ & $15-34$ \\
Elle & $\mathrm{A}, \mathrm{B}, \mathrm{C} 1$ & $15-34$ \\
Prima & $\mathrm{B}, \mathrm{C} 1, \mathrm{C} 2$ & $25-54$ \\
\hline
\end{tabular}

${ }^{a}$ Social class is defined as follows: A-professional, B-managerial and technical, C1-skilled non-manual, C2-skilled manual

Source: data provided were taken from BRAD (British Rates and Data) and indicate the social class and age profile of the majority of readers.

claimed to be "cholesterol reducing," a claim for which there is scientific evidence (see Appendix 1, Advertisement 7), while a cosmetics product was included which claimed to postpone aging, for which scientific support is provided in the advertisement (see Appendix 2, Advertisement 7).

A series of seven food and seven cosmetics advertisements were selected from women's magazines (April-June 2004 issues, see Table 1). The food category (see Appendix 1 for a description of the advertisements used) included three advertisements making explicit use of science-based claims ${ }^{1}$ (Advertisement 7, Flora Pro-Activ; Advertisement 1, Alpro Soya; and Advertisement 2, Müller Vitality), and one making health claims combining scientific information and visual imagery (Advertisement 6, Benecol). The remaining three food advertisements traded on the perceived health benefits of the organic label (Advertisement 3, Go Organic Pasta Sauce), the perceived health benefits of fruit (Advertisement 5, Fruit 'n Fibre) or visual claims relating to being natural (Advertisement 4, Country Life Butter). Products were from the dairy, dairy alternative, organic foods and snack food categories.

Cosmetics advertisements were chosen to reflect categories where scientific claims are made (see Appendix 2 for descriptions of the advertisements used). All products were "experience" products (face creams, deodorants, anti-cellulite and hair care). These included two making explicit claims using scientific and pseudoscientific language (Advertisements 4, RoC, and 7, Clinique), two making claims using pseudoscientific language (Advertisements 5, Vichy, and 3, Dior), one making "natural" and organic claims (Advertisement 1, Tisserand), one making "natural" claims (Advertisement 6, Herbal Essences), and one making a lifestyle claim (Advertisement 2, Nivea). In order to control for the effect of "brand names" in consumer perceptions of this type of product, advertisements were chosen to reflect a range of brand images, from designer to "alternative health" brands.

The results were analyzed using a thematic analysis. Thematic analysis is a form of content analysis that shares many of the principles and procedures of content analysis but is not interested in counting frequencies of occurrence. Rather it has an exploratory interest in emergent patterns for the purpose of theory generation. (The term "thematic" is used loosely to signify the analysis of story-like verbal material, and the use of relatively comprehensive units of analysis such as themes, or what has been called "thought sampling.") While reliability of thematic analysis may be difficult to demonstrate, it operates more as a heuristic than a picture that portrays a precise state of affairs.

In most uses of content analysis, coding categories either are identified in advance of obtaining verbal material on the basis of theoretical or practical considerations, or they are 
derived by classifying responses after they are produced by finding the descriptive categories into which most responses fit. In our exploratory study, we used empirically emergent not theoretically generated themes (Aronson, 1994; Boyatzis, 1998; Hayes, 2000; Joffe and Yardley, 2004; Smith et al., 1992; Taylor and Bogdan, 1984).

Themes were identified based on agreement within and between groups. In addition, cases of disagreement were identified and explored. Thematic analysis of the focus group results is presented under the following categories:

- General attitudes to food and cosmetics,

- Science and health claims in food advertisements,

- Science and health claims in cosmetics advertisements.

General attitudes to food and cosmetics were explored to evaluate whether these product categories could be considered experience products, rather than search products. All three categories are explored in relation to the research objectives listed above.

\section{Results and analysis}

\section{General attitudes to food and cosmetics}

Food was largely seen as a necessity and was not particularly associated with indulgence or enjoyment. For some participants, food was associated with dieting and watching your weight. Organic food was generally viewed as pricey. Fresh fruits and vegetables and oily fish were seen as healthy. There was an indication that "fresh" foods were perceived to be expensive. Attitudes to chocolate, however, were more mixed: some saw it as an aphrodisiac; others attributed healthy aspects to chocolate, such as containing iron. No participants described searching for food products with specific health properties, though health properties were associated with some food categories.

Cosmetics, in contrast, were seen as a luxury or pampering product, or associated with special events. Some perceived cosmetics to be unnecessary and time consuming. Others felt that there was an emphasis on using foreign (specifically French) names for cosmetics to make them sound trendy. The participants also mentioned that there was a bewildering array of cosmetics to choose from. A new trend was perceived to be a move toward natural, fresh, leafy cosmetics products. Price was raised as a concern in two focus groups. Participants highlighted the repeat nature of some cosmetics purchases (e.g. for deodorants) and specifically mentioned the way that some cosmetics might be chosen for the way they make you feel (evaluated post-purchase).

These attitudes suggest that both foods and cosmetics can be viewed as experience products. Foods were clearly identified as necessity products, though issues of expense were raised with organic and fresh foods. Cosmetics were seen to be a luxury product and in some cases were deemed unnecessary. As expected these products were clearly linked with image, both personal and relating to the product itself.

\section{Responses to science claims in food advertisements}

Participants found advertisements that made clear factual statements about what the product is or does most credible. Factual claims could be made through statements or visual imagery. For example, the Benecol Yogurt Drink (Appendix 1, Advertisement 6) was perceived to offer a simple, 
easily understood claim based on the visual elements: "Clever to make the link between the three foods and make the association with milk and apples which are supposed to be good for you."

Science or health based claims for food products that were clear and did not contradict prior knowledge were deemed credible. For example, participants commented about Alpro Soya: "It's non-dairy and low in fat, that's healthy"; "It says it reduces cholesterol." This suggests that some participants were prepared to take science and health claims at face value. They were looking for simple, easy to understand messages and relating these to their scientific knowledge (e.g. that low-fat products are healthy). A similar desire for simplicity was expressed in relation to both the visual imagery and the level of detail in the advertisement.

I prefer the advert with just one image, without loads of details. (a general comment about the food advertisements presented)

I like the simple message, not a crowded message. (stated as a reason for preferring the Benecol advertisement)

However, other participants interrogated claims in more detail, apparently looking for contradictions. These participants showed a degree of skepticism toward the use of science and health claims, especially if information was deemed to be missing and this indicates that participants were using their scientific knowledge to read advertisements more critically. For example, respondents noted:

You need fibre for probiotics to be of benefit, but it doesn't say this. (Müller Yoghurt)

It works because they take something out [fat] but it doesn't say anything about the role of metabolism. (Alpro Soya)

Regarding the yoghurt products (Benecol, Flora and Müller), while some women identified the products as being "healthy" and "reducing cholesterol," they felt the advertisements were vague about how the products worked. Thus, they felt that they ate a healthy diet and exercised and that this was sufficient. These women viewed the advertisements as trying to "push" an unnecessarily expensive new category of foods as "healthy." About such products, one participant commented: "Maybe when you are older-70 — and you go to the doctor and they say to lower cholesterol."

Even when they were open to using "strategically targeted health foods" such as yoghurt drinks, there was an indication that these products were seen to be positioned somewhat like medicines, which must be taken regularly to be effective. For example, this participant clearly suggests that you must take the yoghurt drink regularly for it to be effective: "One a day drinks, you start taking them and then forget" (Benecol).

The advertisements for yoghurts all made functional health claims. These claims appeared to have been believed, as these products were judged to be healthy by most participants. Participants also considered claims to be low in fat or high in fiber as reasons for believing products to be healthy, but mentioned concerns over sugar and preservative content. This again suggests that the participants were drawing on other health related beliefs and knowledge when evaluating the advertisements. "All look or say low fat, but I would look for sugar and other additives before I bought the product." Another respondent commented on the notion that bacteria might have subjective qualities (Müller advertisement), perhaps indicating a skepticism about combining objective scientific claims with subjective language. "I hate the idea of good and bad bacteria."

In the initial discussion of food products, organic foods were seen to be expensive. When it came to evaluating the advertisements, few comments were made about the organic food product (Go Organic). However, one comment supported the tendency to view these products as expensive and their benefits as uncertain. 
I believe people are very easily sucked into organic stuff and to things that are healthy for you. They tend to be expensive. I don't know if they are more expensive because people are willing to pay more or because they are worth more. (in response to Go Organic advertisement)

In relation to the second research objective, the findings suggest that for the food advertisements presented, participants were able to identify scientific claims and draw appropriate conclusions about their meaning. In the case of food products, participants did not express a desire to investigate the validity of the claims made, but were largely prepared to accept them on face value. This supports the categorization of these products as experience products. Phrases such as "lowers cholesterol" and "low fat" were deemed to signal healthy products as were visual images such as fresh fruit (Benecol and strawberries on Flora yoghurt pot). There is also evidence that participants accepted simple "healthy" images at face value with several participants labeling the Fruit 'n Fibre bar as healthy simply because the image showed fresh fruit. The strapline for the advertisement, "fruitier than the average bar," suggests that a high fruit content is desirable and this, together with the image, seemed to persuade participants of the "healthy" nature of the product.

There was, however, a significant minority of participants who were not prepared to take the health claims at face value but indicated that they would seek other information, for example on other nutritional components (such as sugar). Some participants also drew on their scientific knowledge to interrogate scientific and health claims in more detail. It is likely, however, that this evidence of cognitive processing was at least partly a result of the focus group set up, where participants were asked to discuss the advertisements.

\section{Science and pseudoscience claims in cosmetics advertisments}

All groups identified sunscreens with protection against skin cancer. Some participants were informed about a link between cancer and deodorants. They linked deodorants to clogged pores and hair dyes to chemical burns. As with the food advertisements, factual statements were perceived to be credible. For example, of the Clinique advertisement (Appendix 2, Advertisement 7) one participant commented: "It tells you about the product, what it stopsUVA/UVB — and that it moisturises."

However, in contrast to the food advertisements, cosmetics advertisements did not generally inspire credibility.

I don't like any of them. I don't like adverts, they are just trying to sell me something.

Rubbish I'm sure! Cellulite is natural-if you are prone to it, nothing like this can make it diminish significantly! (Dior Bikini Celluli-Diet)

The portrayal of women in the cosmetics advertisements also elicited strong views such as,

I hate adverts with ridiculously perfect/skinny women in them! And she has obviously been really airbrushed-no-one really looks like that. This product can't make you look like the woman in the advert. (Dior Bikini Celluli-Diet)

While the Clinique advertisement was generally trusted, perhaps because participants were familiar with the potential health and aging effects of ultraviolet (UV) irradiation, in most cases scientific language was treated skeptically. "A very scientific approach, $86 \%$ success in tests, but how was it measured" (in reference to the RoC advertisement).

Several of the cosmetics advertisements employed pseudoscientific language and this was treated particularly skeptically. In the case of the anti-cellulite products (Advertisements 3 and 4) and the Vichy skin cream, the pseudoscientific claims were judged implausible, unrealistic and misleading: 
I don't believe that a cream can do everything it states in the advert—seems too good to be true. (Dior Bikini Celluli-Diet)

How do you measure the appearance of imperfections? Wants to sound scientific. (Vichy NormaDerm)

It's scientific nonsense. (Vichy NormaDerm)

They are making claims that if true they would be classed as surgical procedures. Creams can't affect the epidermis. (Vichy NormaDerm)

There was also evidence of some concern about the ingredients contained in cosmetics. For example, the RoC anti-cellulite product was considered risky: "I can't believe a product can do this! What would it really be doing to my skin if I used it?"

Endorsements from well-known breast cancer charities, on the other hand, were seen to improve the credibility of the advertisements (Nivea and Tisserand), with participants widely commenting on the breast cancer charity logos. When asked which cosmetics product appeared most healthy, participants referred to charity logos. Although there has been a link made in the media between cancer and aluminum-containing deodorants, only one participant appeared to be aware of this link, suggesting participants' responses were to the charity logo alone, rather than to any connection between the product and the charity. "The breast cancer logo makes it seem more healthy."

It is clear from these statements that cosmetics advertisements were subjected to more scrutiny and skepticism than the food advertisements were. In contrast to food advertisements, where scientific language and "healthy" imagery were accepted as credible, the opposite appears to hold true for advertisements for cosmetics products. In the case of cosmetics, however, consumers were prepared to accept scientifically proven ingredients (sunscreens) as adding to the product's credibility. Language that was deemed to be "scientific sounding" but without a true scientific basis (e.g. pseudoscientific language) was dismissed as not credible. This suggests that participants were able to negotiate the complex claims made in the cosmetics advertisements used in this exploratory study.

\section{Discussion}

In general, a strong sense of doubt of the credibility of "advertising scientific discourse" was evidenced with regards to advertisements making scientific or pseudoscientific claims for cosmetics products. There was concern that they made false promises, and claims (visual or explicit) that were not supportable. Some particularly felt that the use of jargon (e.g. epidermal disorganization, micro-cysts) was off-putting. This supports the view from Economics of Information theory that claims based on science and pseudoscience are viewed skeptically although in this scientifically aware population this appears to be because the participants found the pseudoscientific language unbelievable rather than difficult to interpret.

In relation to the first objective of the study, it was clear that consumers were more skeptical of cosmetics advertisements than of those for foods. Many of the participants did not view the scientific claims made for cosmetics as objective but rather as credence claims, hence suspicious (Ford et al., 1990). In contrast, advertisements making functional claims for food products were deemed credible when the messages were kept simple and factual ("it says what it does").

How do you measure the "appearance of imperfections"? Wants to sound scientific. (Vichy NormaDerm)

How can you evaluate " $80 \%$ less epidermal disorder”? (Vichy NormaDerm) 
Cosmetics advertisements may have been viewed more skeptically because the claims made were not readily recognized as beneficial and did not fit into an easily categorized health discourse. Claims made for cosmetics products revolved around appearance rather than health per se. The single exception was the Clinique product which tapped into the current sun protection discourse by highlighting the UVA/UVB protection rating of this product and interestingly this advertisement was perceived to be more credible than those of the other creams and anti-cellulite products. In contrast, the health claims made for functional foods tapped into heath related messages that have been current for some time (e.g. low fat, low cholesterol). It may be that participants were less ready to accept claims revolving around a "beauty" discourse because they already held some negative attitudes towards cosmetics products (as unnecessary or expensive), whereas food products were initially conceived as necessary and healthy. Interestingly, amongst the food advertisements the organic product (Go Organic Pasta Sauce) which makes an implicit pseudoscientific claim was viewed skeptically, suggesting that it is the deployment of pseudoscientific claims that triggered a negative reaction in participants rather than the deployment of scientific language.

Regarding the second objective of the study, participants largely found the scientific claims made for food products credible and easy to interpret. This contrasts with studies of the interpretation of nutrition information amongst primary shoppers (Roe et al., 1999; Andrews et al., 2000). In our scientifically aware population there was some evidence that participants felt that some of the claims made were inadequate because they did not provide the whole story. "You need fibre for probiotics to be of benefit, but it doesn't say this" (Müller Yoghurt).

Our research does not provide evidence that objective scientific claims are seen to be more credible than subjective claims for either food or cosmetics products. In many cases the subjective health claims were viewed positively.

I like the tick boxes and it mentions health in the first sentence. (Alpro Soya)

The lady looks in good health, both the lady and the product look natural. (Müller Vitality)

Furthermore, participants often focused on the visual imagery rather than the advertising copy in identifying advertisements that they liked. The Hierarchy of Effects model highlights the importance of liking in the decision-making process. This suggests that it is the advertisements that you like which will have the most impact on your purchasing decisions.

It's pictured with healthy food. (Benecol)

It's clear and simple, not too crowded and has a good image ... that gets the message across. (Benecol)

It was clear that participants brought previous scientific knowledge to bear upon their interpretation of the scientific and pseudoscientific claims made in both cosmetics and food advertisements. In relation to the third objective, there is evidence that this knowledge encouraged participants to take a "central route" to evaluate the advertisements, as predicted by Petty and Cacioppo (1986). When using the central route to process advertising information, consumers consider the advertisement in detail, evaluating the claims made against existing knowledge and prior experience to make a judgment about the believability of the advertising claims. In this case, participants used prior scientific knowledge and conceptions to counter the arguments put forward by the advertisements. This in turn stimulated a negative response to the advertisements:

It works because they take something out [fat] but it doesn't say anything about the role of metabolism. (Alpro Soya) 
They are making claims that if true they would be classed as surgical procedures. Creams can't affect the epidermis. (Vichy NormaDerm)

While such comments indicate that our participants were applying their scientific knowledge to evaluate the advertisements in the context of the focus groups, it is likely that advertisements would not undergo the same level of scrutiny if encountered while flicking through a magazine. However, it is clear that our participants were able to evaluate both cosmetics and food advertisements critically. Interestingly, one participant suggested that she would need to undertake further research into the claims made before she would believe them (evidence of central route processing rather than heuristic processing of the advertising messages). However, most participants did not indicate this level of involvement in processing the advertisements, which supports the Economics of Information theory that readers will dismiss claims for experience products that are deemed unbelievable because it is not worth investing the time in further research for this type of product.

\section{Conclusions and further research}

The participants involved in this exploratory research were chosen because they had a heightened awareness of science. Within this specific group, advertising claims based on science that tapped into current advice were largely believed uncritically. Within this small sample, there is some evidence that awareness of scientific concepts provided the participants with tools to question claims being made and identify missing information. Time limited their ability and interest in pursuing such claims in further detail. In addition, this scientifically literate cohort was largely skeptical of pseudoscientific claims and reacted negatively to the use of pseudoscientific language, particularly in cosmetics advertisements.

The findings of this project relate only to British consumers with a fairly high level of scientific awareness. The present research could usefully be extended to explore the experience of consumers with less scientific awareness who might be more generally representative of the UK population. It would also be useful to extend this exploratory study to examine other categories of experience products. It is possible that the difference seen between cosmetics and food advertisements relates at least in part to attitudes towards these products and that this may account for some of the increased skepticism shown towards cosmetics advertisements and the greater willingness to trust food advertisements.

The research is encouraging in that it suggests that well informed consumers may disregard pseudoscientific language in advertising because the scientific content is too "thin" and uninformative. It is unclear at this stage whether this skepticism translates into altered purchasing behavior. Indeed, there is evidence to suggest that enhanced knowledge and supportive attitudes often have little or no impact on behavior (Bickman, 1972; Geller, 1981; Howard, 2000; Tedeschi et al., 1982).

\section{Note}

1 Throughout, we have defined the category of "science claims" as including claims made for health benefits where there is scientific evidence of the benefit. 


\section{Appendix 1: Description of food advertisements used as stimulus materials}

\section{Food Advertisement 1-Alpro Soya}

\section{Image}

Upper right hand quarter shows a young woman looking up at the camera and holding a spoon with cereal. Her mouth is open as though she is about to eat the cereal. Lower left hand quarter shows the product carton and a bowl of cereal.

\section{Straplines and text}

Upper left hand quarter contains the following text:

Your health is your wealth. Invest wisely for the future.

Lower right hand quarter contains the following text:

Alpro dairy free alternative to milk is one of a new generation of chilled, soya based products that are low in fat, rich in healthy soya protein and delicious.

Lowers cholesterol*

Dairy Free

Low Fat

Rich in Omega 3 \& Omega 6

From the fresh milk section

Dairy free and delicious.

www.alprosoya.co.uk

*The inclusion of at least $25 \mathrm{~g}$ soya protein a day as part of a diet low in saturated fat can help reduce cholesterol in the blood. (This text appears under the product in the lower left hand quarter of the page.)

\section{Food Advertisement 2-Müller Vitality Yoghurt}

\section{Image}

A smiling young woman with her eyes closed (head and shoulders only), apparently naked holding a spoon and a pot of Müller Vitality Yoghurt. At the bottom of the page there is a small heart containing the words "müller vitality."

Strapline and text

Good bacteria with a taste to match 
Your digestive system needs a delicate balance of "good" and "bad" bacteria to stay healthy. Unfortunately, poor diet and lack of exercise can upset that balance. Müller Vitality can help because it's packed with the good probiotic bacteria Lactobacillus Acidophilus and Bifidobacterium as well as inulin, a prebiotic that aids their growth. And with six delicious fruit flavours to choose from, you'll even taste the good it does you.

\section{Food Advertisement 3-Go Organic Pasta Sauce}

\section{Image}

Lower quarter of a woman's face, mouth partly open with an olive between her teeth. Small picture of pasta sauce jar in bottom left hand corner.

\section{Straplines}

Go Orgasmic at the taste of black olives with a little give in the skin

An organic range of sauces and soups

\section{Food Advertisement 4-Country Life Butter}

\section{Image}

Two butter curls shaped as haystacks. The imagery suggests the countryside. Small picture of product in bottom right hand corner.

\section{Straplines}

A taste of Country Life

Freshly Churned English Butter

\section{Food Advertisement 5-Fruit 'n Fibre}

\section{Image}

Fruit 'n Fibre bar standing on end, wearing glasses and a blue scarf tied in a bow at the top of the packet and covered in fruit (grapes, banana, apple).

\section{Strapline}

Fruitier than the average bar

\section{Food Advertisement 6-Benecol Yogurt Drink}

Image

A bottle of milk, an apple and Benecol product arranged vertically one above the other. 
Straplines and text

“Once a day" appears under each image (i.e. three times)

New Benecol Yogurt Drink

Proven to reduce cholesterol

\section{Food Advertisement 7-Flora Pro-Activ range}

Image

Flora Pro-Activ milk bottle and yoghurt pot arranged on a breakfast table with a glass of milk and plates of strawberries, oranges and cherries. The image contains a picture of the sea as background.

\section{Straplines and text}

Two new ways to lower cholesterol

New Flora Pro-Activ in milk and yogurt

Now there's Flora pro.activ in semi-skimmed milk and low fat yogurt. Just like pro.activ spread they contain plant sterols, which are clinically proven to lower cholesterol as part of a healthy diet. Why not find out more at www.floraproactiv.co.uk or call us on 08003898193 Monday to Friday $9 \mathrm{am}-5 \mathrm{pm}$.

\section{Appendix 2: Description of cosmetics advertisements used as stimulus materials}

\section{Cosmetic Advertisement 1-Tisserand}

\section{Image}

Advertisement contains a picture of the deodorant in front of half a lemon (top right hand two thirds). Arranged down the left hand side is the name Tisserand. Under image of the deodorant container are two smaller images, one of a woman using the product and the other a picture of a bottle of tea tree and grapefruit skin wash.

There is a Here's Health Natural Health Awards 2003 Winner logo in the top right hand corner.

The product container clearly states that the product is aluminum and alcohol free.

\section{Straplines and text}

The purest oils from around the world

Pure essential oils

Body oils \& lotions

Shower gels \& soaps 
Bath oils \& soaks

Haircare

Hand \& foot care

Tea tree collection

Lavender collection

Baby range

Candles

Vaporisers

Accessories

$100 \%$ vegetarian

Tisserand aromatherapy

The institute ... for a rewarding career in aromatherapy call 01273206640 Now

Call 01273325666 for details

www.tisserand.com e-mail: info@tisserand.com

There is a Lavender Trust at Breast Cancer Care logo that is placed next to the text: "We are proud to support the Lavender Trust at Breast Cancer Care."

\section{Cosmetic Advertisement 2-Nivea deodorant compact}

Image

A young woman holding the product. She is smiling and looking at the product rather than the reader. Part of her handbag is visible. A Nivea deodorant logo is present in the lower right hand corner of the advertisement.

\section{Straplines and text}

24 hour protection

Lasts up to 80 days

Nivea deodorant compact

The little deodorant that goes a long way. Nivea deodorant compact is pocket-sized, yet lasts as long as a $150 \mathrm{ml}$ aerosol. It's gentle on the skin and gives you 24 hour protection.

24 hour care and protection. 
Nivea is proud to work with Race For Life and women of all ages can join in. Call 08705134 314 or visit www.raceforlife.com (charity logo appears in bottom left hand corner).

\section{Cosmetic Advertisement 3-Dior Bikini Celluli-Diet}

\section{Image}

The torso and upper legs of a thin woman. The woman is largely naked except for a thin pair of knickers. A picture of the product is included to the left of the woman.

\section{Strapline and text}

Divine body! Bikini Celluli-Diet

Bikini introduces its newest slimming innovation with breakthrough technology:

Bikini Celluli-Diet—an essence that helps to "burn fat"*.

Simply spray, no massage required. The appearance of "orange-peel" quickly and visibly diminishes, helping improve skin tone.

Spectacular results: your figure appears slimmer and divinely slender. Your skin looks and feels smoother, softer, more beautiful.

A divine body with Bikini ... your best kept slimming secret!

* in vitro

\section{Cosmetic Advertisement 4—RoC Retinol Body Modelling}

Image

The product appears upside down in the top center of the page. Pointing up at the product is a slender tube that appears to be pressing against firm flesh. The background of the image is suggestive of a person's body. The RoC logo appears in the bottom right hand corner with the strapline: "We keep our promises."

\section{Strapline and text}

New

$20 \%$ reduction.

No suction.

Now you can refine your silhouette without taking drastic measures. Retinol Body Modelling takes the anti-ageing expertise of RoC and applies it to your body. Its unique combination of Retinol, Caffeine and DrainOx Complex works by firming and toning the skin. In just 8 weeks, $86 \%$ of subjects showed an improvement in the "orange peel" appearance of the skin by an average of $20 \% *$, while firmness and tone increased. Figures that add up to a sleeker figure. 
*Clinical study, 44 women. RoC Retinol Body Modelling is a cosmetic cream for the refinement of skin appearance and tone, and is not intended as a replacement for cosmetic procedures.

\section{Cosmetic Advertisement 5-Vichy Laboratoires NormaDerm}

Image

A woman's face (three quarters visible). Part of her face has been cut into jigsaw pieces. The Vichy Laboratoires logo appears in the upper left hand side of the page and the product container appears on the lower right hand side.

Strapline and text

Deep epidermal disorganisation can cause: dilated pores, micro-cysts and imperfections.

\section{NORMADERM}

Anti-imperfection hydrating care with zincadoneA®

Restructures the epidermis to reveal healthy skin in 4 weeks.

Imperfections: $-77 \%$

Dilated pores: $-72 \%$

Micro-cysts: $-74 \%$

Efficiency proven under dermatological control.

Free Normaderm trial kit from your local pharmacy

Hypo-allergenic. With Vichy Thermal Spa Water.

Vichy. Health is vital. Start with your skin.

UK: Exclusively available in independent pharmacies, Lloyds Pharmacy \& Moss Pharmacy Ireland: Exclusively available in pharmacies

1 per customer while stocks last.

\section{Cosmetic Advertisement 6-Herbal Essences}

Image

Head, shoulders and hair of woman apparently asleep in bed. Lower right hand corner contains pictures of the products. 


\section{Strapline and text}

Arouse the sleeping beauty of your hair

New Herbal Essences Shampoos and Conditioners

First stimulate with the all-natural herbs and botanicals of Herbal Essences shampoo. Then revitalise with the new, protein-enriched conditioner containing Hawafena. It's a wakeup call for your hair.

\section{Cosmetics advertisement 7-Clinique Advanced Stop Signs Eye® Preventive Cream SPF 15}

\section{Image}

A clock next to the product container.

\section{Straplines and text}

Age proof eyes?

\section{New Advanced Stop Signs Eye ${ }^{\circledR}$ Preventive Cream SPF 15.}

Moisturizing formula actively helps reduce the visual effects of photoaging of eye-area skin. Incorporates encapsulated sunscreens to help shut out aging UVA and burning UVB rays. Helps reverse the look of fine lines, discolourations. Instantly brightens. See the proof over time. Patent Pending. Allergy tested. 100\% Fragrance free. www.clinique.com

\section{References}

Advertising Standards Association (ASA) (2003) “The CAP Code,” URL: http://www.asa.org.uk/index.asp (accessed 18 October 2004).

Alba, J.W. and Hutchinson, J.W. (1987) “Dimensions of Consumer Expertise," Journal of Marketing 54: $27-41$.

Andrews, J.C., Burton, S. and Netemeyer, R.G. (2000) "Are Some Comparative Nutrition Claims Misleading? The Role of Nutrition Knowledge, Ad Claim Type and Disclosure Conditions," Journal of Advertising 29(3): 29-43.

Aronson, J. (1994) “A Pragmatic View of Thematic Analysis," The Qualitative Report 2(1). URL: http://www.nova. edu/ssss/QR/BackIssues/QR2-1/aronson.html

Bäckström, A., Pirttilä-Backman, A.-M. and Tuorila, H. (2003) "Dimensions of Novelty: a Social Representation of New Foods," Appetite 40: 299-307.

Basch, C.E. (1987) "Focus Group Interview: An Underutilized Research Technique for Improving Theory and Practice in Health Education," Health Education Quarterly 14: 411-48.

Bickman, L. (1972) "Environmental Attitudes and Actions," Journal of Social Psychology 87: 323-4.

Boyatzis, R.E. (1998) Transforming Qualitative Information: Thematic Analysis and Code Development. London: SAGE.

Brucks, M., Mitchell, A.A. and Staelin, R. (1984) "The Effect of Nutritional Information Disclosure in Advertising: An Information Processing Approach,” Journal of Public Policy \& Marketing 3: 1-25.

Chaiken, S., Liberman, A. and Eagly, A.H. (1989) "Heuristic and Systematic Information Processing within and beyond the Persuasion Context," in J.S. Uleman and J.A. Bargh (eds) Unintended Thought: Limits of Awareness, Intention, and Control, pp. 212-52. New York: Guilford Press.

Ford, G.T., Smith, D.B. and Swasy, J.L. (1990) "Consumer Skepticism of Advertising Claims: Testing Hypotheses from Economics of Information," Journal of Consumer Research 16: 433-41.

Franke, G.R., Huhmann, B.A. and Mothersbaugh, D.L. (2004) "Information Content and Consumer Readership of Print Ads: A Comparison of Search and Experience Products," Journal of the Academy of Marketing Science 32(1): $20-31$.

Geller, E.S. (1981) "Evaluating Energy Conservation Programs: Is Verbal Report Enough?," Journal of Consumer Research 8: 331-5. 
Greenbaum, T.L. (1998) The Handbook for Focus Group Research, 2nd edn. Thousand Oaks, CA: SAGE.

Harrison, C. and Brown, I. (2003) "A Comparative Investigation between Functional Foods and their Alternatives with Respect to Medical Claims Made," International Journal of Consumer Studies 27(3): 220-1.

Hayes, N. (2000) Doing Psychological Research. Buckingham: Open University Press.

Heesacker, M., Petty, R.E. and Cacioppo, J.T. (1983) "Field Dependence and Attitude Change: Source Credibility Can alter Persuasion by Affecting Message-relevant Thinking," Journal of Personality 51: 653-66.

Holbrook, M.B. (1978) "Beyond Attitude Structure: Toward the Informational Determinants of Attitude," Journal of Marketing Research 25: 545-6.

House of Lords (2000) Science and Society, Session 1999-2000, Third Report. HL paper 38, February.

Howard, G.S. (2000) “Adapting Human Lifestyles for the 21st Century," American Psychologist 55: 509-15.

Joffe, H. and Yardley, L. (2004) "Content and Thematic Analysis," in D. Marks and L. Yardley (eds) Research Methods in Health Psychology, pp. 56-68. London: SAGE.

Joint Health Claims Initiative (JHCI) (2005) "Joint Health Claims Initiative: Code of Practice on Health Claims on Food," URL: http://www.jhci.co.uk/

Klompenhouwer, T. and van den Belt, H. (2003) "Regulating Functional Foods in the European Union: Informed Choice versus Consumer Protection?," Journal of Agricultural and Environmental Ethics 16: 545-56.

Krueger, R.A. (1998) Analyzing and Reporting Focus Group Results. Thousand Oaks, CA: SAGE.

Kwak, N.-S. and Jukes, D.J. (2001a) "Functional Foods. Part 1: the Development of a Regulatory Concept," Food Control 12: 99-107.

Kwak, N.-S. and Jukes, D.J. (2001b) "Functional Foods. Part 2: the Impact on Current Regulatory Terminology," Food Control 12: 109-17.

Morgan, D.L. (1996a) "Focus Groups," Annual Review of Sociology 22: 129-52.

Morgan, D.L. (1996b) Focus Groups as Qualitative Research, 2nd edn. London: SAGE.

Petty, R.E. and Cacioppo, J.T. (1986) Communication and Persuasion: Central and Peripheral Routes to Attitude Change. Berlin: Springer Verlag.

Roddick, A. (1991) Body and Soul. London: Ebury Press.

Roe, B., Levy, A.S. and Derby, B.M. (1999) "The Impact of Health Claims on Consumer Search and Product Evaluation Outcomes: Results from FDA Experimental Data," Journal of Public Policy \& Marketing 18(Spring): 89-105.

Royal Society (1985) The Public Understanding of Science (The Bodmer Report). London: The Royal Society.

Seal, D.W., Bogart, L.M. and Ehrhardt, A.A. (1998) "Small Group Dynamics: the Utility of Focus Group Discussions as a Research Method," Group Dynamics: Theory, Research and Practice 2: 253-66.

Smith, C.P., Atkinson, J.W. and McClelland, D.C., eds (1992) The Handbook of Thematic Analysis, pp. 419-27. New York: Cambridge University Press.

Taylor, S.J. and Bogdan, R. (1984) Introduction to Qualitative Research Methods: The Search for Meanings. New York: John Wiley \& Sons.

Tedeschi, R.G., Cann, A. and Siegfried, W.D. (1982) "Participation in Voluntary Auto Emissions Inspection," Journal of Social Psychology 117: 309-10.

\section{Authors}

Rachel Dodds now works as a Science Communication Officer for Cardiff University and is currently completing an M.Sc. in Science Communication. Her experience also includes the coordination of public engagement projects from Techniquest science center.

Efrat Tseëlon gained a D.Phil. in Social Psychology from Oxford University and has since developed into a multi-disciplinary scholar. She has researched and published in areas of visual identities, personal appearance, and methodological critique. Her current research interest and activity centers on ethics in consumption and design. She holds the chair in fashion theory at the School of design, University of Leeds.

Emma Weitkamp gained a Ph.D. from Cambridge University and is a Senior Lecturer in Science Communication at the University of The West of England. She is interested in how scientific messages in the mainstream media influence behavior and the role of scientific information in consumers' decision-making processes. Correspondence: Faculty of Applied Sciences, The University of the West of England, Frenchay Campus, Coldharbour Lane, Bristol BS16 1QY, UK; e-mail: emma.weitkamp@uwe.ac.uk 